Running Head: MANAGEMENT AND GOVERNANCE OF RESIDENTIAL GOLF DEVELOPMENTS

An examination of management and governance issues arising in residential golf complexes

\author{
Chris Guilding \\ Griffith University
}

and

John Whiteoak

University of the Sunshine Coast 
An examination of management and governance issues arising in residential golf complexes

\begin{abstract}
This study provides an examination of governance issues arising in residential golf communities. A residential golf community can be referred to as a multi titled golf development (MTGD) where separately titled houses and a golf course coexist within an identifiable estate that typically has a single road entry point. The study's objectives are to outline typical governance arrangements concerning the assignment of rights between accommodation owners and golf course entities in Queensland MTGDs, and to explore the nature of governance challenges arising in connection with the assignment of rights between these two parties. Drawing on qualitative data collected from thirteen interviews with Queensland-based developer representatives and body corporate managers experienced in MTGDs, it has been found that there is a legislative trend towards accommodation owners experiencing diminished levels of influence on golf course management and operations. All interviewees felt this to be the most appropriate model for future MTGDs. It is nevertheless noted that this development signifies a degree of neighbourhood disenfranchisement for residential owners and that a poorly managed golf course can negatively influence residential property values and political harmony in an MTGD.
\end{abstract}




\title{
An examination of management and governance issues arising in residential golf complexes
}

\author{
Introduction
}

This study focuses on the governance structuring of multi titled golf developments (MTGDs) in Queensland, Australia. The archetypal Queensland MTGD comprises a golf course owned by one party, a strata titled residential estate owned by a separate set of parties and some residual land and infrastructure for which ownership and a form of governance has to be established. According to Ball (1984) a strata titled scheme refers to a subdivision of land and / or buildings into units, which can be owned separately, and common property, which is owned communally. The law in Australia concerned with strata titled complexes has arisen in a somewhat ad hoc reactionary manner following increased urbanization and a growing need to regulate tightly clustered independent owners (Christudason, 1996).

Integrated residential and golf course complexes have become popular in the last fifteen years, yet there is a paucity of academic research directed at developing an appreciation of the management and governance issues arising in these systems. The absence of prior research provided the broad motivation for the study reported herein.

The study has two objectives. Firstly we seek to outline typical governance arrangements concerning the assignment of rights between accommodation owners and golf course entities in Queensland MTGDs. Secondly, we seek to explore the nature of governance challenges arising in connection with the assignment of rights between these two distinct parties that co-exist in MTGDs. Queensland was selected as the site for this investigation for several reasons. First, Australian multi title law is state based rendering 
a study that focuses on all of Australia somewhat problematical. Second, Queensland has a temperate climate that is highly conducive to golf, and significant development of MTGDs in Queensland has occurred in the recent past. Third, Queensland legislature is widely regarded as being the most comprehensive and at the forefront of Australian multi title law (Everton-Moore, Ardill, Guilding and Warnken, 2006).

The remainder of the paper is organised as follows. The next section overviews the most pertinent literature. The qualitative data collection research method applied is then described. This is followed by a section providing legal context to the empirical observations described in the ensuing section. The paper concludes with a discussion of the main findings. Several specific suggestions concerning ways that further research could advance the understanding of this largely neglected realm of management and community living governance are also presented.

\section{Literature review}

No prior study with a focus on governance and management issues arising in MTGDs has been found. Perhaps even more surprising, with the notable exception of Blandy, Dixon and Dupuis' (2006) study, there is a paucity of governance and management enquiries in the broader field of strata titled housing. This signifies that a challenging aspect of this study concerns the identification of an appropriate literary context in which to ground the empirical work. Aside from Blandy et al's (2006) study, the two most pertinent literatures identified concern a fledgling literature that focuses on issues arising in tourism based multi titled properties and the generic golf management literature. These literatures form the basis of the review provided here. 
Blandy et al (2006) provide a longitudinal framework comprising three critical legal events occurring in the governance evolution of a multi-titled complex. These three events are: 1) A contract between developer and managing agent (generally referred to as a "body corporate" or "strata manager" in Australia) is signed; 2) A collective (widely referred to as a "body corporate" in Australia) representing individual lot owners is established; 3) Developer's representative interests in the owners' collective declines as new owners buy lots in the scheme. Blandy et al., then draw on theoretical perspectives on power (e.g., Bourdieu, 1987; Foucault, 1980), and empirical observations made in New Zealand and the UK to comment on governance factors arising as multi titled property ownership is transferred from the developer to the eventual individual title owners. Blandy et al's fundamental observation concerns the inconsistency between the passage of ownership from developer to the individual property owners and the constrained influence assumed by individual property owners following their title purchase.

It appears that an aging population, a boom in property prices and adept marketing of 'lifestyle' by property developers, has stimulated multi titled developments that include, detached villas, duplexes or townhouses, and low or high-rise apartment complexes, to become a popular style of living for many Australians. The impact is particularly notable in many tourism regions (e.g., Australia's Gold Coast), where multi title has become the primary vehicle for new tourist accommodation developments (Warnken, 2002; Warnken, Russell and Faulkner, 2003). In their examination of the relationship existing between managers and owners in Australian multi titled tourism accommodation properties, Guilding, Ardill, Fredline, and Warnken. (2005) note that the 
Australian multi titled tourism accommodation sector represents an investment of over AUS \$8.75 billion.

The complex nature of the multi titled tourism accommodation sector is further outlined by Guilding, Ardill, Warnken, Cassidy and Everton-Moore (2006) who note the involvement of at least eleven distinct stakeholders. This complexity is amplified by the fact that each Australian state and territory has its own legislative provisions pertaining to multi titling (Everton-Moore et al., 2006). State based legislation also applies in the United States of America where multi titled properties tend to be referred to as 'condominiums' that are run by 'community associations'.

It appears that as the use of multi title style developments has become more popular with developers and real-estate brokers, attention has been directed to the potential of using golf-facilities to add value to large real estate and resort developments (Warnken, Thompson and Zakus, 2001). In fact, most new golf courses are now developed in conjunction with real estate (Hodges and Haydu, 2004; Lum, 2003), and the days of developing stand-alone golf courses appear to be largely over (Blondin, 2006). For example, Hodges and Haydu (2004) note that 54\% of Florida golf courses are integrated with a residential development, and that these residential units are estimated to be worth US\$158 billion. A significant implication of this is that the layout of golf courses is becoming dependent on the best way to maximize real-estate sales around the course. Blondin (2006) states that in the United States current golf course based real estate development is not limited to new golf courses as many established golf courses are being redeveloped in order to introduce a real-estate precinct. 
Many developers use golf courses as a loss leader designed to generate high accommodation property returns. The 'loss leader' concept applies in those situations where the golf course does not have 'stand alone' economic viability, yet it has the capacity to support higher prices for adjacent accommodation properties. Hodges and Haydu (2004) found that a golf course would significantly increase the value of properties within a one mile radius in $67 \%$ of cases.

Although the 'loss leader' concept presumes that residential property proximity to a golf course is a desirable and value-enhancing feature, Warnken et al., (2001) suggest that the growth of loss leader type golf facilities has significant negative environmental consequences. They note that oversupply can increase price competition and constrain operating budgets, ultimately leading to economic failure of the development. The presumed property value enhancement stemming from golf-course proximity may in some cases have limited long-term sustainability. For example, Asabere and Huffman (1996) and Hodges and Haydu (2005) have observed cases where close proximity to a golf course has carried a negative impact on real estate values. Asabere and Huffman suggested this might be due to factors such as golf ball hazards and traffic noise.

Although the marriage of golf and accommodation in the context of an integrated development brings novel managerial and governance challenges, no prior research examining this issue has been found in the literature. The golf-management literature tends to be more dominated by examinations of operational and technical issues such as on course speed-of-play and maximizing available tee-off times (Chen, 2004; Kimes, 2000), course maintenance (Shmanske, 1999), player satisfaction levels and motivations 
(Petrick and Backman, 2002) and environmental considerations (Chen, 2004; Warnken et al., 2001).

Method

The data collection method employed for this study involved conducting multiple case studies involving face-to-face interviews. A multiple case study design was considered appropriate for this research due to a limited literature and the potential for a great deal of variation in the way MTGDs are developed.

The sample for this research was purposively generated in two ways. Initially a face-to-face interview was conducted with an industry expert known to the research team. This industry expert was able to provide the research team with potential contacts who could inform the study. This initial interview was also used to develop the interview protocol. Following this, a listing of golf clubs attached to residential developments was established and senior managers responsible for managing the properties contacted by phone and invited to participate in the study. It should be noted that an in-depth qualitative study approach such as that undertaken in this study is not purporting to be based on a representative sample of all stakeholders of the population of interest. Rather, it was considered that a purposive sampling approach that focused on experienced professionals and those most closely involved with MTGDs had the potential to yield rich and insightful data.

Given the exploratory nature of this research, both researchers were present at the first five interviews. This enabled the deployment of deeper probing techniques and greatly facilitated the data analysis process. In addition, this approach ensured that similar 
questioning and probing techniques were used consistently during the latter, individually conducted, interviews.

Theoretical convergence was reached (Yin 2003) after a total of 13 interviews had been conducted. The pertinence of the study's focus to MTGD managers was evident from the fact that all potential subjects contacted consented to be interviewed. An overview of the subjects interviewed is provided in Table 1. The first column provides an alphabetical reference for each interviewee that is used in the subsequent text whenever citing an interviewee's comment. The second column provides a brief description of the nature of each subject's MTGD experience. It is believed that this sample represents the substantive knowledge base with respect to strata titling of golf developments in South East Queensland.

The interviews were conducted in a semi-structured manner and lasted for approximately one hour. The interview protocol developed for the study was guided by Miles and Huberman's (1994) recommendation that researchers should seek to limit the probes to no more than a dozen questions in all. The questions posed focused on the interviewees' perceptions of eight issues:

- the evolution of legislation affecting MTGDs,

- $\quad$ issues surrounding voting entitlements in MTGDs.

- the relative segregation of accommodation precinct governance from golf club governance,

- implications arising from the degree of accommodation owners' influence on the golf club,

- political issues arising in MTGDs, 
- the golf club as community centre,

- the involvement of specialist strata managers,

- problems arising from accommodation purchaser naivety.

Creswell (2003) suggests that an interview protocol should be designed with one or two central questions in mind. All of the questioning conducted in the interviews focused on the governance domain of MTGD management, and in particular factors surrounding the relative influence of accommodation owners on golf course management.

During the analysis phase, the data was organized categorically and reviewed repeatedly. Identification and description of patterns and themes from the perspective of the subjects and then an attempt to understand and explain these patterns and themes was undertaken, as suggested by Agar (1988). There was a high degree of consensus amongst the researchers concerning the emergent themes. Care was taken to apply a systematic analytical protocol in an attempt to promote completeness and lack of bias in the collection and analysis of the data (Lillis, 1999). Despite this, consistent with the view of Mertens (2004), like any research based on qualitative data, it should be acknowledged that the background of researchers is bound to introduce some biases in the way that themes in data collected are discerned and prioritised. As an important final step to add validity to the findings, two key interviewees were asked to review a draft version of the paper. They both concurred that the results appropriately depict governance issues arising in South East Queensland MTGDs.

In the description of findings that follows, excerpts from the transcribed interviews are provided as support or exemplifications of issues described. In some cases, it has been necessary to reduce the length of the quote cited. In such instances, three full 
stops $(\ldots)$ have been inserted into the text to signify that words provided by the interviewee have been excluded. The utmost care has been taken to ensure that in applying this approach, the context and intent of what the respondent stated has not been distorted or altered.

\section{Insert Table 1 about here}

Because each Australian state has its own legislation pertaining to MTGDs, an early decision was made to focus the study on a single state. The selection of Queensland as the focus of the study is supported by the following response provided by Interviewee B when asked whether Queensland represents a leader in multi titled golf resort development:

"Yes pretty much. Queensland had the means because of population growth and the type of development that happened and in 1997 the current legislation and Body Corporation and Community Management Act came onboard with its different modules. .... That was cutting edge in terms of legislation."

Legal Context for the Examination of Governance Issues

This section provides legislative context for the study by outlining and interpreting the significance of recent Queensland acts pertaining to the development of MTGDs. In providing an overview of the evolution of large integrated multi titled resort 
legislation in Queensland, the interviewees tended to make early reference to The Sanctuary Cove Act 1985 (SCA). Typifying this, Interviewee D commented:

"I suppose it all starts with Sanctuary Cove - that was the first one. There was really nothing before Sanctuary Cove because this was the first one that had to have its own act."

The SCA instituted a three tier body corporate governance framework (see Figure 1). ${ }^{1}$ The workings of this framework will be described in a generic manner, because, as will be noted below, the SCA provided a model that was largely replicated in the subsequent Integrated Resort Development Act, 1987. The top echelon of the framework is referred to as the primary thoroughfare body corporate (PTBC). The PTBC is responsible for maintaining all common MTGD property areas that do not fall under the jurisdiction of more specifically defined ownership titles. Areas of a MTGD that come under the governance and responsibility of the PTBC include the main entry to the MTGD and the roads connecting the various precincts that comprise the MTGD (e.g., the golf course, residential estates, etc.). The generic term 'body corporate' refers to the collection of property owners who own lots of freehold land that are associated with a 'community titles scheme'. A community titles scheme arises where land comprises two or more lots and contains common property that is not part of the lots (Ardill, EvertonMoore, Fredline, Guilding and Warnken , 2004).

Insert Figure 1 about here

\footnotetext{
${ }^{1}$ The somewhat path breaking nature of the Sanctuary Cove Act was evident from comments made by the interviewees. In light of this and the fact that it laid the foundation for subsequent similar legislation, a diagrammatic representation of the management structure created by the act is provided.
} 
The PTBC is governed by the PTBC committee which comprises representatives drawn from the second tier of the body corporate governance framework. This second tier comprises commercial entities (e.g., golf club, marina, hotel site, commercial precincts and cultural centre) and also the principal body corporate (PBC) which represents the owners of accommodation properties in the MTGD. These distinct elements at the second tier of the body corporate governance framework are often referred to as precincts, as they occupy distinct physical areas within the MTGD. Each of the precincts are accorded a number of voting entitlements that define relative influence on the PTBC committee. A controlling influence on the PTBC comes at a cost, however, as voting entitlements determine PTBC levy contribution levels. A 51\% voting entitlement signifies the responsibility of providing $51 \%$ of the total PTBC levies raised.

The third tier of the body corporate governance framework arises where there is more than one residential precinct with its own body corporate in the MTGD. Where this occurs, each residential precinct's body corporate is referred to as a subsidiary body corporate. Each subsidiary body corporate is then represented, in turn, on the principal body corporate committee. Experience has shown that the number of subsidiary precincts is usually determined by the degree to which they are physically distinct from one another, have distinctive landscaping or road related features giving rise to particular maintenance needs, or distinctive building configurations (eg., high-rise, landlocked, high-density and retirement village).

The SCA was passed specifically for the Sanctuary Cove MTGD project and could not be used for any other projects. As several other MTGD proposals were formulated shortly after the passing of the SCA, it became apparent that more generic 
legislation was needed and the Integrated Resort Development Act (IRDA) was passed in 1987. The IRDA applied the same basic model as that established in the SCA. From the perspective of the contracting parties and the governance model established, the interviewees saw relatively insignificant differences between the two acts.

A key facet of the frameworks outlined in the SCA and the IRDA was the provision that the golf club be part of the integrated body corporate framework. This changed with the passing of the Body Corporation and Community Management Act 1997 (BCCMA), as under the provisions of this legislation the golf club operates independently from the body corporate structure (for a commentary on this Act and also recent amendments legislated in 2002 and 2003, see Ardill et al., 2004).

Interviewee D felt a particular strength of the BCCMA was its relative simplicity, as it signifies only two tiers of body corporate governance, i.e., at the individual residential precinct level and the combined residential precincts level. He commented:

"This makes it far easier to run and because each of the people in the subsidiary scheme elects a representative to the principal scheme they should know what is going on."

This view was endorsed by Interviewee A:

"They (the residents) have no involvement with hotels and all those types of things and all of a sudden it just simplified the operation structure because they now can't go off and make trouble for anyone else and once people know that, they kind of 'stick to their knitting' and we found the angst is less. .... and developers seem to have more freedom with people who are interested in buying and selling their non-residential product." 
Despite the passing of the BCCMA, it is important to recognize that each Queensland MTGD is governed according to the legislative provisions in place at the time the MTGD was developed. This is significant, as many extant Queensland MTGDs were established prior to the BCCMA.

A key issue arising from the legislation that predates the BCCMA concerns the relative influence of the parties represented at the PTBC level of MTGD governance. Several of the interviewees expressed unprompted views on the allocation of PTBC voting entitlements. It became evident that it was customary practice for the developer to ensure it maintained a controlling influence on the PTBC for the duration of the period that the MTGD is under development (as noted later, this can span more than twenty years). Interviewee A commented:

Most of the time, the developer will have to escalate what their lot entitlements are so they can get the power to vote at the compromise of actually having higher holding costs. The more votes they have the more they have to pay towards the community."

When asked as to why equivalent voting entitlements are not allocated to each of the parties comprising the PTBC, Interviewee B commented:

"Because they want control mechanisms in place so that residential areas couldn't tell commercial areas what to do."

As an extension to this view, Interviewee $\mathrm{H}$ provided the following justification:

"I can only assume, looking at the way the mechanics of it happen, that it was meant to favour developer-based interests over the residential based interests, and probably because the property of that primary thoroughfare body corporate was 
that main entry road, and I guess the traffic on that would tend to be heavier if it were going to those commercial zones."

This view highlights a guiding doctrine of allocating governance power over an asset to that party making greatest use of the asset.

Any negative inference arising from this reference to developers seeking to favour their own interests should be qualified, however. Although MTGD residents may have limited PTBC influence in MTGDs created under legislation predating the BCCMA, Interviewee D did note that "this is compensated for by the fact that in many MTGDs, the residents command some commercial power due to the golf club's dependency on MTGD residents purchasing golf club memberships."

Also, as noted above, greater voting entitlements signify the assumption of greater body corporate contribution levies. The cynic might argue that the higher levies are a small price for the developer to pay to maintain control over its commercial interest and the direction of the MTGD. There is a more persuasive position that counters this view, however. It appears appropriate that while a developer is still developing a MTGD, it should retain the capacity to direct outstanding building works in a manner consistent with the MTGD master plan that has been made publicly available to all who have already purchased lots within the developing MTGD.

An obvious governance legacy arises out of the old MTGD legislation, however. Should the developer sell its commercial lots in the MTGD to another commercial enterprise (many developers appear to see this as the final step taken in their long-term MTGD plan), the new commercial owners will assume a controlling influence on the PTBC. From the perspective of a potential purchaser of a commercial lot in a MTGD 
with a relatively large infrastructure falling under the PTBC's jurisdiction, the negative implication of substantial levies associated with commercial lot ownership might be perceived as a greater liability than the benefit deriving from holding a controlling position on the PTBC. It appears likely that any reduced commercial property values arising from relatively high contribution levies would be viewed by developers as a necessary and small price to pay in the context of maintaining a capacity to realize a MTGD's master plan. Further, the diminished value associated with selling any commercial properties carrying high PTBC levies will, in many cases, be a projected cash flow that will not be received by the developer for many years following the MTGD's initial development. This deferred sale of MTGD commercial entities signifies that their value will be significantly lessened when discounted back to the time that the developer initiates the MTGD development.

Because of the important governance issues arising from the allocation of voting entitlements, an exploration of the rationale adopted by developers in their allocation of voting entitlements would have been a potentially fruitful line of research enquiry. To conduct such an enquiry in the context of the current Queensland legislation would, however, be a somewhat anachronistic endeavor due to the changed governance implications arising from the BCCMA.

The relationship between residential property owner and golf club management could be considered from an agency perspective (Berle and Means, 1962; Jensen and Meckling, 1976; Lambert, 2001), whereby the golf club manager is cast as the agent and residential property owners collectively represent the principal. This perspective would be particularly pertinent if a residential property owner were to be given an equity stake 
in the golf club. Under the SCA and IRDA, however, the residential property owners' golf club influence is diminished sufficiently that it might be a misnomer to refer to them as having a principal stake in the complex. Under the BCCMA, it would certainly be inappropriate to view the residential property owners as having a principal standing in the MTGD. The continuum in terms of 'principal influence' represented by these three different contexts is believed to provide a useful insight into the significance of different MTGD governance models.

\section{Results}

In this section, governance and managerial issues arising in multi titled golf developments are examined under the following headings: segregating the influence of accommodation owners and the golf club, accommodation owner disenfranchisement, and political issues arising in MTGDs.

Segregating the influence of accommodation owners and the golf club

With respect to golf club management, the preferred MTGD model espoused by most of the interviewees was consistent with the BCCMA, whereby accommodation owners have no formal way to influence golf course management. The BCCMA governance model signifies that the golf course management's influence is restricted to the golf course and the MTGD accommodation owners' influence is restricted to all areas falling outside the golf course and any other commercial precincts.

In justifying this model, the interviewees tended to highlight rationales formulated from the accommodation owner perspective. Featuring predominantly in this perspective 
is the desire of accommodation owners to minimize their body corporate levies. In a manner characterising this view, Interviewee D commented:

"If the residents were to have more control over the golf course, then it would need to be common property and their body corporate fees would be enormous. Essentially they can't afford it."

Interviewee $\mathrm{F}$ expanded on this position highlighting that not all potential accommodation owners want to have part ownership of, and play on, the golf course:

"Our preferred model, or what we would recommend at the moment, is to not have the golf course as part of the scheme, keep it out because it is traditionally harder and more expensive to maintain and its not lot owners' best interest to have that as common property. .... You don't want to compel all your buyers to be members of the golf course and to have to pay the cost."

Departing slightly from this position, it was observed that in the MTGDs where Interviewees I and L worked, golf club membership was provided as a result of purchasing an accommodation unit. This membership provided a right to play, but no right to exert any managerial or governance influence over the golf club. This arrangement appeared atypical, however, as most interviewees felt that a significant proportion of MTGD accommodation property owners had little interest in playing golf.

Interviewee A extended this accommodation owners' perspective by commenting on risk and insurance obligations that would arise from assuming a stake in the golf club. He commented:

"Other issues that residents have realised with being a part of a golf course facility is liability. So separating the golf course out of the community, people are saying 
'I don't really mind that because we can't be tied up in legal situations', and people know that if something happens and if they can sue a body corporate, they will because of body corporates' great insurance policies. So they don't like nonresidential in their body corporate because it does escalate their responsibilities and liabilities."

Some interviewees also justified segregating the influence of accommodation owners from commercial operators by offering a rationale from the commercial operators' perspective. Interviewee B saw problems occurring if accommodation owners are able to wield significant influence over the golf club. He commented:

"The relationship between the two will be by way of easement and that easement will set out how much the town centre pays the principal body corporate to maintain the common roads and gardens, etc. The commercial entity will not have to be at the beck and call then of the principal body corporate."

In a similar vein, Interviewee A commented:

"What was being found by developers is that operations of these non-residential areas are being interfered with, albeit at a small level, because the residents are there and they can use the body corporate as a vehicle to frustrate or control nonresidential products."

Interviewee $\mathrm{F}$ saw the segregation issue from the perspective of both camps and noted that golf course values can suffer when accommodation owners exert influence on the club's management. He observed:

"The risk profile of having the golf course attached to the body corporate is just too high. The advice from lawyers involved from other projects has been that the 
valuation of the golf club could be negatively affected by having the body corporate involved, and if the market perceives it this way, it affects the money they pay."

Some interviewees also felt that the interests of the accommodation owners and golf club operators were too incompatible to enable a healthy working relationship to develop. Interviewee A commented:

"Whenever we got the residents and the non-residential lots together they always had different objectives and therefore there was conflict. One wants to bring as many people in and have it as loud and more enjoyable experience as you can, while the other wants quiet enjoyment."

Similarly, Interviewee B commented:

"I personally don't see that there should be any need for residents to have any great input into the commercial area. They both have conflicting views."

In terms of which party benefits most from segregating golf club interests from accommodation owners' interests, it appeared that the interviewees felt that the main beneficiary is the golf club. Interviewee B commented:

"I do feel that the golf club need not be too concerned about the residents, but the residents could be quite concerned that the golf course is going to be run well."

Similarly, Interviewee A commented:

"Residents want as much in a body corporate as possible because they can use that as a form of control. Non-residential lots don't want to be part of a body corporate .... If we put those lots in a residential body corporate they will discount the value by $15 \%$." 
It had been anticipated that some MTGD property maintenance economies of scale would be realised if the manager in charge of golf course maintenance were to also assume responsibility for outdoor maintenance of the residential precincts. While such an arrangement might be intuitively appealing, Interviewee A dismissed it as not workable:

"They (golf managers) want nothing to do with anything else. Absolutely nothing, because they have enough work to do just looking after the golf course. In fact, they will ignore everything in the world to look after the golf course. We've actually tried to negotiate golf course operators to maintain the residential estate, because they have all the fantastic equipment. They already have the manpower, but they just treat it as a poor cousin and they never look after to a standard that we want. So invariably, they kind of by-pass them altogether and they just operate the golf course."

This observation appears as insightful as it signifies that a justification of the segregation of golf course affairs from the affairs of the residential estate can be provided on operational grounds, in addition to the governance based rationales already outlined. It should be noted, however, that other management structures, such as the resident owners holding a controlling management interest in the golf club, could affect this tendency.

Accommodation owner disenfranchisement

Several of the interviewees commented on the developers' primary motivation for developing MTGDs. They noted that close proximity to a golf course serves to promote MTGD residential unit sales. Interviewee E commented: 
Management and Governance of Residential Golf Developments - 23 -

"The golf course is built specifically to help market the residential component. .... (Refers to a particular golf course) was predominantly put on land that could not have residential development put on it, because it was a flood plain; the reason it was economically developed as a course. .... There are not many golf courses that make money, so therefore the golf course has got to be there as the loss leader."

A similar view concerning the role of the golf course as a marketing loss leader was evident in comments provided by Interviewee F:

"It's never there to make money as a golf course. It might one day make enough to cover its own sinking fund, but it will never be a profitable business."

This role of the golf course as a marketing vehicle for promoting the sales of MTGD accommodation units signifies that a significant part of the value associated with a MTGD accommodation unit derives from the extent to which the value adding source (ie., the golf course) is appropriately maintained. ${ }^{2}$ This capacity of a golf course to add value to residential properties located close to the course is particularly apparent from Interviewee B's following comment:

"With regards to (names a MTGD), and I don't mean to be critical of the set up down there, but that is a classic example (where) the operation of the golf club has deteriorated and therefore I think it has directly impacted on the developer's ability to move his residential stock. The developer can't move his stock and that is going to hurt the development company. .... The developer is loosing money hand over fist."

\footnotetext{
${ }^{2}$ This factor signifies that a potential purchaser of an MTGD residential property should investigate the nature and motivation of the golf club. If it is a commercially run enterprise, it will have a strong incentive to sustain its course maintenance standards. If it is a non-profit entity, the incentive to maintain the course in a good condition is not as apparent.
} 
The potential for a MTGD golf course to become run down is also evident in the following comments provided by Interviewee C:

"At (names a MTGD) the golf course runs at a loss and no one will take it over because it is a horrific loss. People put these things in to attract people. In the long term there could be degradation in the golf course because no one can afford to run it and it turns into a weed infested thing that one or two people play on every year. (Names another golf course) has deteriorated in 10 years."

The extent to which proximity to a golf course can add value to a residential property was not explicitly examined in this study, however it could be usefully investigated in subsequent research by drawing on the value theory literature (Brown, 2007). The fact that an MTGD accommodation unit derives much of its desirability, and hence value, from appropriate maintenance and running of the golf course highlights a fundamental shortcoming in the segregated accommodation owner / golf club MTGD governance model promoted in the BCCMA. MTGD property owners have a vested interest in maintaining the golf facility at a high standard, yet they have limited ability to protect this source of value in their vested interest. Despite this a priori shortcoming, when raised with the interviewees they appeared to see it as little more than an undesirable by-product of their preferred model.

The main deficiencies of the segregated model commented upon by the interviewees concerned the need for well designed by-laws, easements and dispute procedures. Indicative of this, when asked what improvements he would suggest for the segregated model, Interviewee G commented: 
"Probably have more robust contractual conditions in the access easements, easements licenses and that sort of thing; but really document. You really have to spell out what's going to happen and have a dispute procedure and that sort of thing in there. So if the body corporate and the golf course management get into a dispute, there's got to be some nominated arbitrator or nominate some way of getting a resolution on how to get a quick answer on things."

\section{Political issues arising in MTGDs}

As intimated by much of the earlier discussion, it appears that the level and nature of the fractionally-based interaction arising in the MTGD context is such to provide a high propensity for individuals and groups to act in a political manner. Two comments provided in the interviews appear to be particularly insightful in this regard. Interviewee C commented:

"These schemes can be extremely political - we have just had absolute anarchy over at (names a MTGD) and are still having it right now. If you walk over there now you would find blood on the streets. There has been a coup, so there are political body corporate problems but not management/organisational problems. It can be like watching federal politics, we are not there to participate in the political processes. The problems are often about openness and transparency - people want to have a say in what is happening."

It was also apparent that the MTGD political issues are not vested solely at the property level. As is evident from Interviewee H's following comments, they can be aired much further a field: 
"Politics are rife through all of these structures. Our approach is always just to play things with a straight bat, explain our commercial motives at all times and hope that will appeal to the majority of the people, the majority of the time. But there have been instances where we have proposed particular developments which have not suited that residential community at all and they play the full political game. Whether that's complaining up my hierarchy to get me to change what I do, whether it's taking us all on as a management team, Sydney head office included, and complaining about us to the local politicians or the local counselor or the Premier. That happens on a regular basis and these are typically, fairly well connected people so they do have good access to stakeholders in this process. Equally, what it compels us to do is maintain contact with all of those stakeholders as well, so we maintain pretty good relationships with local and state government bureaucracy at all sorts of levels."

\section{Conclusion}

Following an extensive literature search, it is believed this study represents the first academic study to explore the somewhat idiosyncratic context for governance procedures established in MTGDs. The focus of the study should be considered in this light as it constitutes a scoping and exploratory work. As there was scant literature that the study could build upon, an early decision was taken to undertake interviews, as this approach provided the research team with the opportunity to seek out data richness.

The objectives of the study were to outline typical governance arrangements concerning the assignment of rights between accommodation owners and golf course 
entities and also to explore the nature of governance challenges arising in connection with the assignment of rights between these two distinct parties. The overview of the evolving Queensland legislation pertaining to the governance of MTGDs has provided a very clear picture that accommodation owners in MTGDs now experience greatly diminished levels of influence on golf course management and operations. While all interviewees felt this to be an appropriate development, the resultant neighbourhood disenfranchisement signifies that accommodation owners can do little when poor golf course management negatively impacts on their property values. These observations constitute manifest contributions to the literature, particularly as no prior related research has been found. In light of the paucity of prior research, is it is hoped that this study will provoke further studies concerned with the idiosyncratic management and governance issues arising in MTGDs and constitute a useful foundation stone upon which such endeavour can be built.

It appears as noteworthy that the findings indicate negligible concern held by the interviewees in connection with residential owners' diminished capacity to exercise influence over a determinant of part of their property's value. As the number of interviews conducted does not permit confident generalization, however, it could well be that a broader cross-section of interviewees may yield further observations pertaining to this issue. The somewhat perplexing nature of this finding suggests it might be worthy of further research enquiry. Further, it may well be the case that in other countries it is common for golf course equity entitlements to be allocated amongst accommodation owners. If a jurisdiction could be found where this is a widely used approach in MTGD, it would be interesting to explore the relative merits of this alternative approach to 
structuring the relationship between the golf club and residential property owners. Comments made by one of the interviewees suggested that this model may well be used more widely in some Asian countries.

It appears from the data collected that a developer's rationale for including a golf course within the physical context of a distinct housing complex is frequently motivated by little more than a desire to enhance the value of the associated MTGD residential properties. While this appeared to be the case in several of the MTGDs visited in the course of conducting this study, it should not be implied that it is always the case. For those complexes located close to land that has a propensity to flood, the developer's option to create a golf course on the flood plain is immediately more viable and can be pursued with limited consideration given to the financial return that the golf course can generate as an independently operated commercial entity. This is because no foregone house sales result (ie, opportunity costs) from the golf course development. This absence of an opportunity cost lowers the need for the developer to be able to demonstrate that the golf course can be run as an independent viable entity. For those MTGD golf courses located on land that could have been used for housing, the need to demonstrate a viable commercial return for the golf course as an independently run entity is much greater. Golf courses built where a housing sale opportunity cost is incurred can only be justified if the complex comprises up-market housing with a capacity to command greatly inflated prices and the golf course has the capacity to generate a viable commercial return that is likely to be based on a prestigious image strongly associated with a sense of exclusivity. Our understanding of these significant issues could be facilitated by the collection and analysis of further research data provided from the developer's perspective. Should 
further data be sought from developers, insights pertaining to their perception of golfers' demand for MTGD golf courses could also prove illuminating.

As this is believed to be the first study internationally to have undertaken a governance based investigation of issues arising in golf course based master communities, it is believed to have the potential to command considerable international interest. Although legislative provisions vary across international and state boundaries, the pertinence of the paper is not likely to be diminished by the particular legal jurisdiction of the reader, as the fundamental challenge of determining what influence residents should have over golf course management (and vice versa) in a golf course based master planned community can be expected to represent an omnipresent conundrum to be wrestled with by planners of all golf course based communities internationally.

It should be noted that this study suffers from many of the limitations generally associated with qualitative field research. These limitations include the degree of subjectivity that is bound to be invoked by researchers when conducting interviews and analysing data collected, and also the fact that the size of the sample precludes any confident generalisation of the findings to a wider population. For this reason, the study's findings should be viewed in an exploratory light. This shortcoming highlights the significant contribution that could derive from conducting a survey of MTGD governance issues and practices. Such a survey could investigate several of the issues raised in the paper, although to achieve a robust sample size the survey would most likely have to move beyond the confines of one Australian state. Future researchers interested in this area will need to be mindful of the particular legal jurisdiction in which they conduct 
their analysis. Despite this warning, it is believed that most of the issues raised in this paper will be common to legal jurisdictions in most Western countries.

A particular shortcoming of the research design applied in this study stems from the fact that no owners of residential properties located within MTGDs were interviewed. Further research that focuses on the perceptions of MTGD residential property owners is to be encouraged. Such research could re-examine some of the governance issues appraised herein and also seek to determine the motives for purchasing MTGD residential properties. The thrust of such an enquiry could also draw on value theory which concerns how people positively and negatively value physical constructs such as the materials used in building a house and non-physical constructs such as the proximity of a house to a golf course. 
Management and Governance of Residential Golf Developments - 31 -

\section{$\underline{\text { References }}$}

Agar, M.H. (1988) Speaking of Ethnography, Thousand Oaks, California: Sage Publications.

Ardill, A. K., Everton-Moore, L., Fredline, C., Guilding, and Warnken, J. (2004), Community titles reforms in Queensland: A regulatory panacea for commercial, residential and tourism stakeholders, The Queensland Lawyer, Vol. 25, pp.13-27.

Asabere, P. K., and Huffman, F. E. (1996), Negative and positive impacts of golf course proximity on home prices, The Appraisal Journal, Vol. 64, pp.351-355.

Ball, R. (1984), What is a multi-title?, Law Institute Journal, August, pp.924-925.

Berle, A. A., and Means G. C. (1967), The modern corporation and private property, Harcourt, Brace \& World: New York.

Blandy, S., Dixon, J., and Dupuis, A. (2006), Theorising power relationships in multi-owned residential developments: Unpacking the bundle of rights, Urban Studies, Vol. 43, pp.2365-2383.

Blondin, A. (2006), Housing market sets future of golf courses, Knight Ridder Tribune Business News, Jan 22.

Bourdieu, P. (1987), The force of law: Toward a sociology of the juridical field, The Hastings Law Journal, Vol. 38, pp.814-853.

Brown, C. (2007), Two kinds of Holism About Values, Philosophical Quarterly, $57,456-463$.

Chen, T. (2004), A study of golf courses management: The in-depth interview approach, Journal of American Academy of Business, Vol. 5, pp.138-143. 
Management and Governance of Residential Golf Developments - 32 -

Christudason, A. (1996), Subdividing buildings: Developments in Australia, Singapore and England, International and Comparative Law Quarterly, Vol. 45, pp.343364.

Creswell J.W. (2003), Research Design: Qualitative, Quantitative, and Mixed Methods Approaches, $2^{\text {nd }}$ ed, Thousand Oaks, California: Sage Publications.

Everton-Moore, K., Ardill, A., Guilding, C., and Warnken, J. (2006), The law of multi-title in Australia: A jurisdictional stocktake, Australian Property Law Journal, Vol. $13,1-35$.

Foucault, M. (1980), Power/Knowledge. Harvester Press: Brighton.

Guilding, C., Ardill, A., Fredline, E., and Warnken, J. (2005), An agency theory perspective on the owner / manager relationship in tourism-based condominiums, Tourism Management, Vol. 26, pp.409-420.

Guilding, C., Ardill, A., Warnken, J., Cassidy, K., and Everton-Moore, K. (2006), Investigation of the multi-titled tourism accommodation sector in Australia: Legal context and stakeholder views, Co-operative Research Centre for Sustainable Tourism Technical Report, Griffith University: Gold Coast.

Hodges, A. W., and Haydu, J. J. (2004), Golf, tourism and amenity based development in Florida, Journal of American Academy of Business, Vol. 4, pp.481-488.

Kimes, S. E. (2000), Revenue management on the links, Cornell Hotel and Administration Quarterly, Vol. 41, pp.120-127.

Jensen, M., and Meckling, W. (1976), Theory of the Firm: Managerial behavior, agency costs and ownership structure, Journal of Financial Economics, Vol. 3, pp.305360. 
Management and Governance of Residential Golf Developments - 33 -

Lambert, R. A. (2001), Contracting theory and accounting, Journal of Accounting and Economics, Dec, 3-87.

Lillis, A.M. (1999). A framework for the analysis of interview data from multiple field research sites, Accounting and Finance, 39:1, 79-105.

Lum, R. (2003), Course management lofty business for firm, Baltimore Business Journal, Vol. 20, pp.24-25.

Mertens, D.M. (2004), Research Methods in Education and Psychology:

Integrating diversity with quantitative, qualitative, and mixed methods. $2^{\text {nd }} \mathrm{ed}$, London: Sage Publications.

Miles, M.B and Huberman A.M. (1994), Qualitative Data Analysis, $2^{\text {nd }}$ ed, Thousand Oaks, California: Sage Publications.

Ryan, R., Scapens, R. W., and Theobald, M. (1992), Research Method and Methodology in Finance and Accounting, Academic Press: London.

Shamske, S. (1999), The economics of golf course condition and beauty, Atlantic Economic Journal, Vol. 27, pp.301-313.

Warnken J. (2002). Tourism Infrastructure Audit - Gold Coast, Project 2.2 of the Gold Coast Visioning Project CRC Research Report Series. Gold Coast: Co-operative Research Centre for Sustainable Tourism, Griffith University: Gold Coast.

Warnken, J., Russell, R., and Faulkner, B., (2003), Condominium developments in maturing destinations: Potentials and problems for long-term sustainability, Tourism Management, Vol. 24, pp.155-168. 
Warnken J., Thompson, D., and Zakus, D. H. (2001), Golf course development in a major tourist destination: Implications for planning and management, Environmental Management, Vol. 27, pp.681-696.

Yin, R. K. (2003). Case Study Research: Design and Methods ( $3^{\text {rd }}$ ed.). London: Sage Publications. 
Table 1

Description of interviewees' MTGD experience

\begin{tabular}{|c|c|}
\hline Interviewee & MTGD Experience \\
\hline A & $\begin{array}{l}\text { Works for a large body corporate management service provider. Interviewee A has } \\
\text { developed a specialist consulting service in connection with the establishment and } \\
\text { management of MTGDs. }\end{array}$ \\
\hline B & $\begin{array}{l}\text { Works for the developer of a large MTGD as the on-site body corporate manager. This } \\
\text { MTGD has established several distinct residential communities in the development and } \\
\text { further residential building was underway at the time of data collection. }\end{array}$ \\
\hline $\mathrm{C}$ & $\begin{array}{l}\text { Works for an independent body corporate management service provider that has } \\
\text { contracted to provide body corporate management and also facility management } \\
\text { services to a large MTGD. The extent of this engagement is such that Interviewee C } \\
\text { has an office at the MTGD. }\end{array}$ \\
\hline $\mathrm{D}$ & $\begin{array}{l}\text { Works for a large body corporate management service provider and has gained many } \\
\text { years of experience in MTGD body corporate management. At the time of the } \\
\text { interview, Interviewee D was providing body corporate management service to a large } \\
\text { MTGD that included a hotel, marina and residential housing. }\end{array}$ \\
\hline $\mathrm{E}$ & $\begin{array}{l}\text { Acts as a freelance consultant providing specialist advice in connection with multi title } \\
\text { property ownership and management and ownership; has more than twenty years of } \\
\text { experience in the industry. }\end{array}$ \\
\hline $\mathrm{F}$ & $\begin{array}{l}\text { Works for a large body corporate management service provider and has a particular } \\
\text { responsibility for advising developers of integrated resorts that involve a multi titled } \\
\text { component (eg., MTGDs). }\end{array}$ \\
\hline G & $\begin{array}{l}\text { Development manager working for a property developer in an established golf course. } \\
\text { Accommodation properties were under construction at the time of the interview. }\end{array}$ \\
\hline $\mathrm{H}$ & $\begin{array}{l}\text { Senior officer with a property developer in an established golf course. Accommodation } \\
\text { properties were under construction and being marketed at the time of the interview. }\end{array}$ \\
\hline I & $\begin{array}{l}\text { Project director of a large property owning enterprise that has purchased designated } \\
\text { development land in an existing MTGD. }\end{array}$ \\
\hline $\mathrm{J}$ & Works as the sales and marketing manager in the same company as Interviewee I. \\
\hline $\mathrm{K}$ & Works as the project manager in the same company as Interviewee I. \\
\hline $\mathrm{L}$ & Manager of a golf-based country club. \\
\hline M & $\begin{array}{l}\text { Associate director with a land corporation that is operating in a joint venture as the } \\
\text { developer of a MTGD. Responsibility brief concerns directing the project sales team. }\end{array}$ \\
\hline
\end{tabular}


Management and Governance of Residential Golf Developments - 36 -

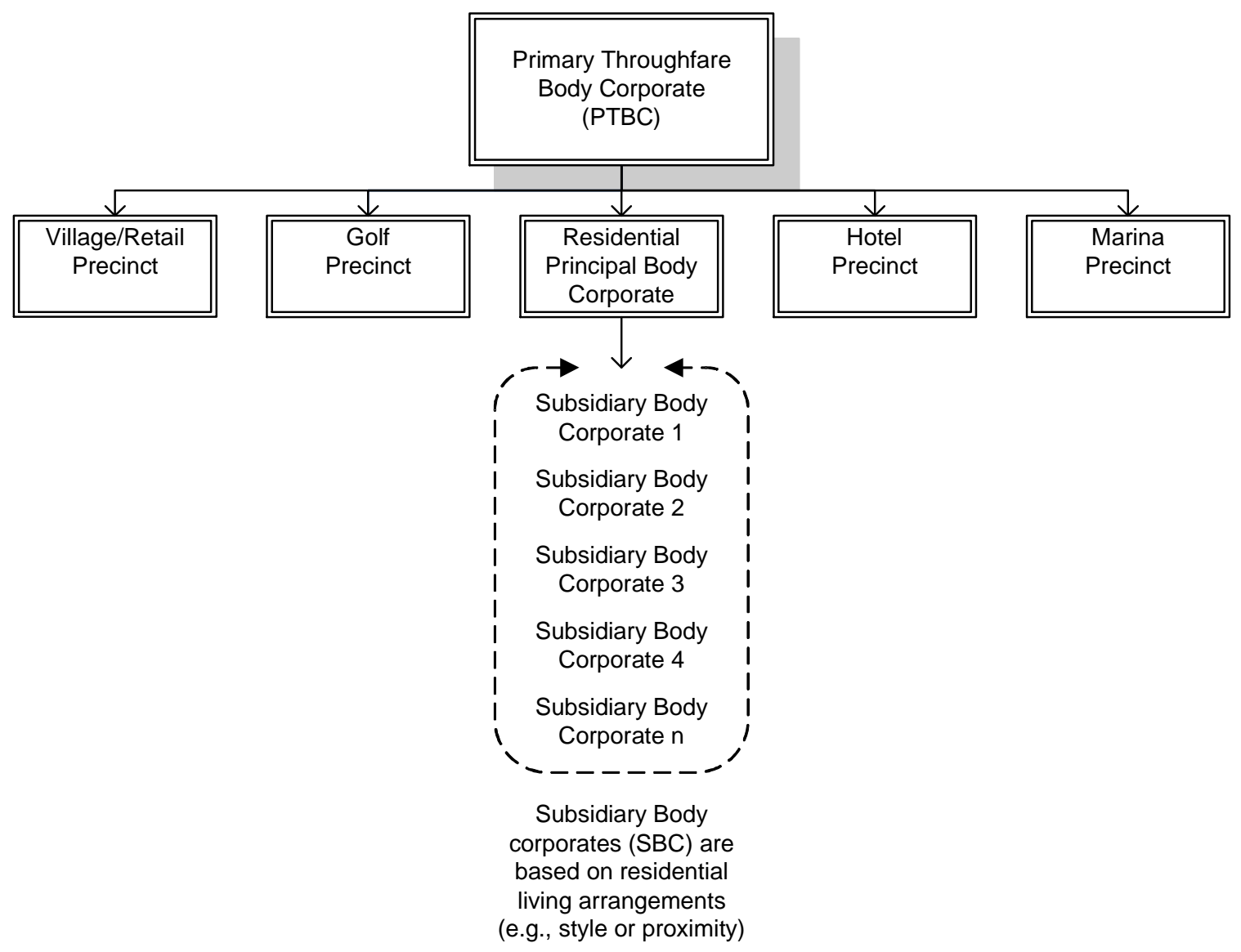

Figure Caption

Figure 1. The Sanctuary Cove Act MTGD governance structure 